\title{
O USO DE ÁLCOOL POR ADOLESCENTES DO COLÉGIO ESTADUAL ALFREDO NASSER - URUAÇU/GO
}

\author{
Gleidison Moura Costa ${ }^{1}$; Neila Maria Mendes Borges²; Maristela \\ Vicente de Paula ${ }^{3}$
}

\section{Resumo}

O consumo de álcool é uma realidade em nosso meio, sendo considerado um problema de saúde pública. O que mais impressiona é que mesmo sendo uma droga, o início desse consumo tem ocorrido cada vez mais cedo, o que aumenta o risco de dependência, problemas no desenvolvimento e,no futuro, como o aparecimento de doenças. São aumentadas também, as chances de envolvimento em acidentes, violência sexual e participação em gangues, além do que, o álcool é considerado a porta de entrada para outras drogas. Este artigo tem por objetivo avaliar o padrão de consumo de álcool entre os alunos adolescentes do Ensino Médio de uma escola situada em Uruaçu-GO. Como objetivos específicos, buscamos: a) discorrer sobre a permissividade quanto ao consumo de álcool por adolescentes; b) apresentar as leis que versam sobre o assunto e as políticas voltadas ao tema; c) apresentar os prejuízos que o consumo de álcool pode ocasionar ao indivíduo em formação; d) descrever informações a respeito do consumo por adolescentes;

1

Especialista em Direitos Humanos da Criança e Adolescente. Uruaçu-Goias. Brasil. Email: gleidison10@yahoo.com.br

2

Mestre em Educação Física. Professora no curso de Educação Física da Universidade Federal de Goiás. Catalão-GO. Brasil. Email: neilamariamendes@gmail.com

3

Mestre em Educação Física. Professora no curso de Educação Física da Universidade Federal de Goiás. Catalão-GO. Brasil. Email Email: maristela.vicente.paula@gmail.com 
e) verificar a quantidade de álcool consumida e de que forma esse consumo é feito: se o consumo é em grande quantidade numa única ocasião, o que é bastante prejudicial e perigoso, ou se esse consumo costuma ocorrer de forma mais leve, cujos efeitos são menos danosos, mas, em sendo contínuo esse consumo, pode indicar possível início de dependência. Esta pesquisa trata-se de uma pesquisa de campo de caráter descritivo e exploratório realizada entre 62 alunos do Ensino Médio de uma escola situada em Uruaçu-GO escolhidos por acessibilidade e conveniência, utilizando como instrumento de coleta de dados o Teste de Identificação de Desordens devido ao Uso de Álcool (AUDIT). Mesmo sendo legalmente proibido para menores de 18 anos no Brasil, os resultados apontam que é comum o uso de álcool por adolescentes. Na pesquisa realizada com jovens de 15 anos de idade, em média $67 \%$ afirmaram fazerem uso de bebidas alcoólicas: homens (87\%) e mulheres (46\%). Apesar do alto índice de usuários, a pesquisa mostrou que o padrão desse consumo ainda é de baixo risco $(87,5 \%)$ e aqueles que fazem uso considerado como de risco (12,5\%). No entanto, como não há níveis seguros para a ingestão dessa substância e sabe-se que, quanto mais precocemente se inicia esse consumo, maiores são as chances de problemas no futuro, além da vulnerabilidade em que essa parcela da população se encontra, maior atenção deve ser dada para que este problema não se agrave ainda mais.

Palavras Chave: adolescência; álcool; escola 